\title{
Delineation of the population genetic structure of Culicoides imicola in East and South Africa
}

Maria G. Onyango ${ }^{1,2}$, George N. Michuki ${ }^{3}$, Moses Ogugo ${ }^{3}$, Gert J. Venter ${ }^{4}$, Miguel A. Miranda ${ }^{5}$, Nohal Elissa ${ }^{6}$, Appolinaire Djikeng ${ }^{3,7}$, Steve Kemp ${ }^{3}$, Peter J. Walker ${ }^{1}$ and Jean-Bernard Duchemin ${ }^{1 *}$

\begin{abstract}
Background: Culicoides imicola Kieffer, 1913 is the main vector of bluetongue virus (BTV) and African horse sickness virus (AHSV) in Sub-Saharan Africa. Understanding the population genetic structure of this midge and the nature of barriers to gene flow will lead to a deeper understanding of bluetongue epidemiology and more effective vector control in this region.

Methods: A panel of 12 DNA microsatellite markers isolated de novo and mitochondrial DNA were utilized in a study of C. imicola populations from Africa and an outlier population from the Balearic Islands. The DNA microsatellite markers and mitochondrial DNA were also used to examine a population of closely related C. bolitinos Meiswinkel midges.

Results: The microsatellite data suggest gene flow between Kenya and south-west Indian Ocean Islands exist while a restricted gene flow between Kenya and South Africa C. imicola populations occurs. Genetic distance correlated with geographic distance by Mantel test. The mitochondrial DNA analysis results imply that the C. imicola populations from Kenya and south-west Indian Ocean Islands (Madagascar and Mauritius) shared haplotypes while C. imicola population from South Africa possessed private haplotypes and the highest nucleotide diversity among the African populations. The Bayesian skyline plot suggested a population growth.

Conclusions: The gene flow demonstrated by this study indicates a potential risk of introduction of new BTV serotypes by wind-borne infected Culicoides into the Islands. Genetic similarity between Mauritius and South Africa may be due to translocation as a result of human-induced activities; this could impact negatively on the livestock industry. The microsatellite markers isolated in this study may be utilised to study C. bolitinos, an important vector of BTV and AHSV in Africa and identify sources of future incursions.
\end{abstract}

Keywords: Culicoides imicola, Culicoides bolitinos, Bluetongue virus, Mitochondrial DNA, Arboviruses, Population structure

\section{Background}

Biting midges of the genus Culicoides (Diptera: Ceratopogonidae) are vectors of a number of arboviruses infecting livestock. Of the 75 arboviruses associated with Culicoides, 15 have been isolated from species belonging to C. imicola complex [1]. The C. imicola complex (C. imicola, C. bolitinos, C. brevitarsis, C. nudipalpis, C. kwagga, C. Ioxodontis,

\footnotetext{
* Correspondence: Jean-Bernard.Duchemin@csiro.au

${ }^{1} \mathrm{CSIRO}$ Health and Biosecurity, Australian Animal Health Laboratory,

5 Portalington Road, Geelong, VIC 3220, Australia

Full list of author information is available at the end of the article
}

C. miombo, C.pseudopallidipennis, C. tutti-frutti and C. asiatica) $[2,3]$ contains the three most important known vectors of bluetongue virus: C. imicola, C. bolitinos and $C$. brevitarsis.

Culicoides imicola is widely distributed in Africa, the Mediterranean, India, Laos, Vietnam and southern China [1, 2, 4, 5]. It is capable of transmitting both bluetongue virus (BTV) and African horse sickness virus (AHSV) [5-7] and is considered to be the most important vector of these viruses in Africa [8]. Bluetongue disease was first described in 1903 in 
South Africa and was initially referred to as malarial catarrhal fever [9]. A total of 21 (numbered as 1-19, 22 and 24) serotypes have been identified in Africa [10]. South Africa currently has all 21 serotypes) [11]. Further north, in Kenya, 19 BTV serotypes have been isolated from sentinel cattle but clinical disease is not evident among the indigenous sheep [12]. A recent study in Madagascar revealed a very high prevalence of BTV serotype 2 in cattle and large distribution of the virus amongst domestic ruminants [13]. In 2003, the first outbreak of BTV (BTV-3) occurred in the neighbouring Island of La Reunion [14] and at least four serotypes (BTV-2, 17, 10 and 21) have been detected circulating in deer from Mauritius [15].

Presently, African horse sickness virus (AHSV) is endemic in tropical and sub-tropical areas of Africa south of the Sahara (East Africa, West Africa) extending as far south as the north of South Africa [16, 17]. Outside Africa, the disease is endemic in Yemen [17, 18]. However, the occurrence of AHS outbreaks in the Maghreb (western North Africa), then in Spain in 1965-66 and 1987-1990 indicates the epidemiological situation is fragile for non-endemic regions such as Europe or Madagascar and Mauritius [19]. In the absence of a wildlife reservoir, the trade-related movements of cattle and horse from one place to another is considered as the main driver of outbreak spread [20], but the hypothesis of Culicoides movement either passive or active cannot be ruled out. Because of their small size, Culicoides can be passively dispersed over long distance by prevailing winds [21]. Long distance wind dispersal of Culicoides has been incriminated for the introduction of novel bluetongue virus serotypes and genotypes to new areas [22-24].

With such a rich diversity of bluetongue and AHSV serotypes circulating in the south and east of Africa, understanding the genetic structure of their vector C. imicola may give insights into the epidemiology of these diseases and further uncover possible transmission routes which could prevent future expansion into disease-free countries [25]. Given the geographical barriers (islands) within the south-west Indian Ocean region, we hypothesize a higher degree of restriction of gene flow between the islands and the continental mass than within the continent.

Despite its importance as a vector, there is scarce information about the population genetic structure of $C$. imicola in Africa. Sebastiani et al. [26] demonstrated molecular differentiation of the old world C. imicola species complex from southern Africa, Madagascar and the Ivory Coast. Using random amplified DNA (RAPD) markers, polymorphic bands that resulted in species-specific RAPD profiles were used to carry out molecular analysis of variance (AMOVA) test in order to assess the allelic variation between and within the species populations. A high level of intra-population genetic differentiation and a relatively lower level of inter-population genetic differentiation were observed. Madagascar populations of C. imicola s.s. revealed isolation by distance pattern. Mardulyn et al. [27] study used microsatellite markers to study genetic variation among C. imicola populations from southern Europe and North Africa and performed approximate Bayesian computation framework analysis on the allelic variation obtained by microsatellite genotyping. The findings supported a weak population structure between northern Africa C. imicola populations and southern Europe populations of $C$. imicola that led to the conclusion of a possible ancient existence of $C$. imicola in Europe.

Utilizing the same mitochondrial and microsatellite markers developed by Mardulyn et al. [27], Jacquet et al. [28] have also demonstrated the ancient existence of $C$. imicola in Europe and the possible routes of incursions of C. imicola into Europe from Africa. Using the mitochondrial gene marker cytochrome oxidase I (COI) Desvars et al. [29] found a lack of genetic connectivity between $C$. imicola populations from Reunion Island, Spain and South Africa.

This study was designed to provide quantitative data about genetic differentiation of the C. imicola populations within the East and South regions of Africa. It has considered the potential geographical and physical factors, acting as barriers or motors to gene flow and dispersal. Technically, the first aim of this study was to develop de novo DNA microsatellite markers for $C$. imicola using a recently described experimental workflow [30]. The second aim of the study was to employ both the developed microsatellite markers and DNA sequences of the COI gene to test genetic diversity amongst geographically different populations from Balearic Islands, Kenya, South Africa, Madagascar and Mauritius. The third aim was to utilise the novel microsatellite markers designed for C. imicola to amplify microsatellite repeats of the closely related species $C$. bolitinos, an important vector of BTV and AHSV in sub-Sahara Africa.

\section{Methods \\ Collection of midges}

The collection sites for midges used in this study are shown in Fig. 1 and Table 1. A total of 138 C. imicola midges were collected from the Balearic Islands, Kenya, South Africa, Madagascar and Mauritius and 5 samples of $C$. bolitinos midges were collected from Madagascar. Samples of both C. imicola and C. bolitinos were collected using traps set at night $1 \mathrm{~h}$ before sunset to around $0800 \mathrm{~h}$ at dawn. The samples were transported to the laboratory in $70 \%$ ethanol. Morphological identification was based on the wing patterns [31] observed using a binocular microscope. Species identification was 


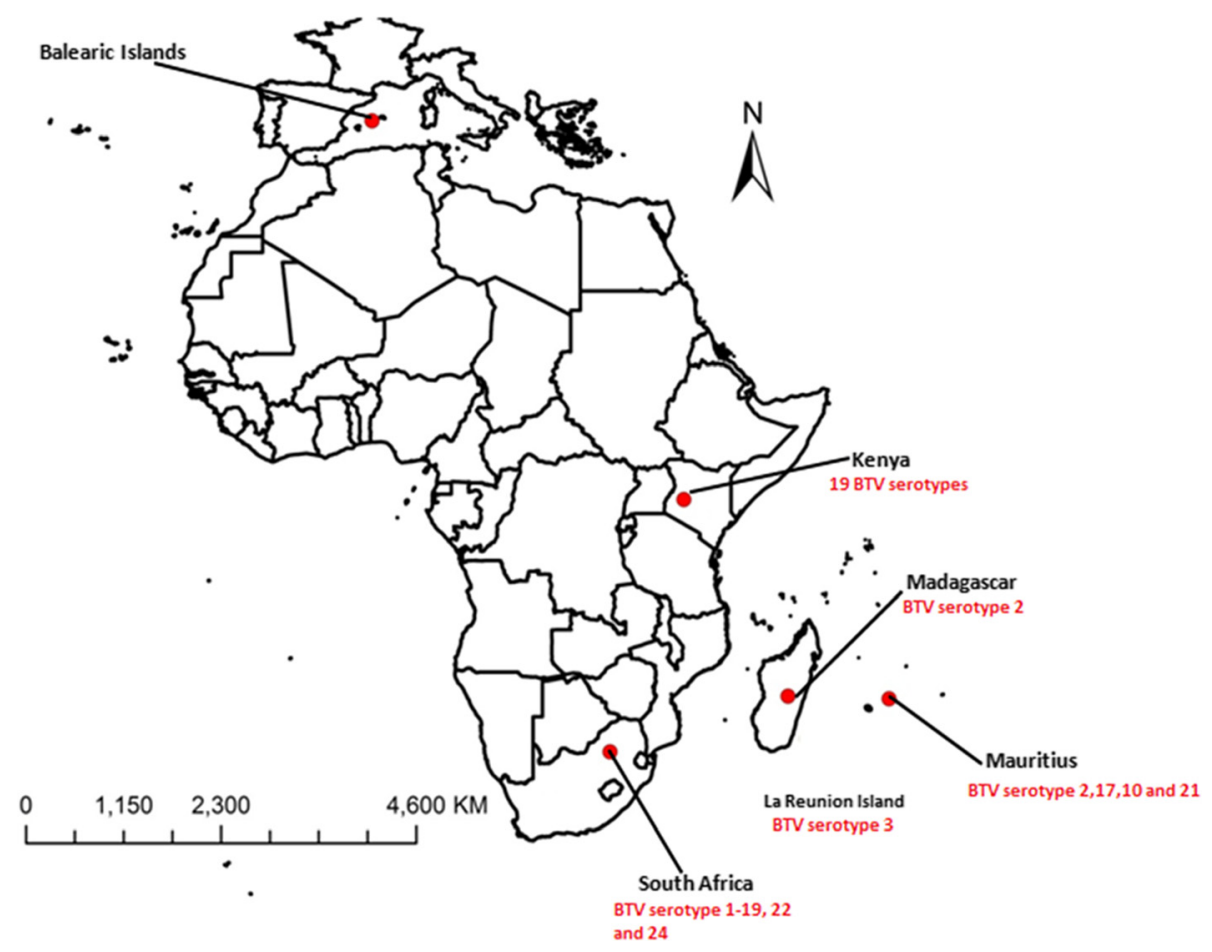

Fig. 1 Map showing Culicoides imicola collection sites and serotype distribution in Africa. Map source: Arc Map

confirmed by amplification of the $m t \mathrm{DNA}$ COI gene [2] to ensure exclusion of morphologically similar species.

\section{Cytochrome oxidase I (COI) gene amplification and sequencing}

The $m t D N A C O I$ gene was amplified from 83 individuals (Kenya, South Africa, Madagascar, Mauritius and Balearic Islands) [GenBank numbers: KT339684- KT339742; KT945260-KT945271; KT968152- KT968163] using primer pair Bc1 Culic Fm (GTA AAA CGA CGG CCA GTT CWA CWA AYC AYA AAR WTA) and JerR2m (CAG GAA ACA GCT ATG ACC CAA ARA ATC ARA AYA RRT GTT G) [32]. The amplification was carried out under the following conditions: Initial denaturation of $94{ }^{\circ} \mathrm{C}$ for $2 \mathrm{~min}, 40$ cycles of $94{ }^{\circ} \mathrm{C}$ for $30 \mathrm{~s}, 50{ }^{\circ} \mathrm{C}$ for $30 \mathrm{~s}, 72{ }^{\circ} \mathrm{C}$ for $1 \mathrm{~min}$ and a final elongation step of $72{ }^{\circ} \mathrm{C}$ for $5 \mathrm{~min}$. Each $25 \mu \mathrm{l}$ PCR reaction included
$1.0 \mu \mathrm{l}$ template DNA (20 ng), $0.2 \mu \mathrm{mol}$ each of forward and reverse primer, $18 \mu \mathrm{l}$ Platinum PCR supermix high fidelity (Life Technologies) and $2.75 \mu \mathrm{l}$ de-ionized water. The PCR amplicons were purified using QIAquick PCR purification kit (Qiagen) and $20 \mu \mathrm{l}$ was sequenced using the Sanger sequencing method (Macrogen, Geumchun-gu, Seoul).

\section{Phylogenetic and demography history analysis of mitochondrial DNA (mtDNA)}

The sequences were aligned using MUSCLE [33] and then trimmed to a uniform length. A total of 11 previously identified and published haplotypes (Greece and Israel) were added with the following GenBank accession numbers: [AF078098 - 100, AF080531-2, AF080534, AJ549388-92] [6, 34]. To examine phylogenetic relationships, haplotype networks were constructed in PopART [35] using TCS

Table 1 A table of the sites of midges collection with the locations and global positioning system coordinates of Culicoides imicola samples from Spain and Africa. The collection method used was the CDC light trap

\begin{tabular}{|c|c|c|c|c|c|c|}
\hline Species & Region & Site & Latitude & Longitude & n (Microsatellite) & n (Mitochondrial DNA) \\
\hline C. imicola & Kenya & Marigat & 0.47 & 35.99 & 26 & 21 \\
\hline C. imicola & Balearic Islands & Mallorca & 39.61 & 2.95 & 24 & 14 \\
\hline C. imicola & Madagascar & Ambalavao & -21.83 & 46.93 & 25 & 17 \\
\hline C. imicola & Mauritius & Poste Lafayette & -20.14 & 57.75 & 35 & 13 \\
\hline C. imicola & South Africa & Onderstepoort & -25.65 & 28.18 & 28 & 13 \\
\hline C. bolitinos & Madagascar & Ambalavao & -21.83 & 46.93 & 5 & 5 \\
\hline
\end{tabular}


network (95 \% connection limit). The historical demographical processes were inferred using several methods. Haplotype diversity (h), nucleotide diversity $(\pi)$ and neutrality tests (Fu's F's and Tajima's D) were computed in Dna Sp v.5 [36] and Arlequin v 3.11 [37].

A coalescent-based Bayesian skyline plot was utilised [38] to estimate the effective population size. This method uses the Markov chain Monte Carlo (MCMC) procedure to estimate the posterior distribution of effective population size. The analysis was conducted using the HKY substitution model with empirical base frequencies, with each codon having its own rate of evolution and a strict clock model enforced. A total of 10 000000 iterations were run, a burn-in of 1000000 , while the parameters of the model were stored every 1 000 iterations. The Bayesian phylogenetic analysis were carried out using BEAST v1.8.2 [38]. The posterior distributions and the graph were plotted using TRACER v1.6 software.

\section{Isolation and validation of microsatellites markers}

De novo isolation of microsatellite DNA was carried out using a recently-developed workflow [30]. In brief, genomic DNA was obtained from four pools of midges (each pool consisting of 15 samples) from Kenya, Madagascar, Balearic Islands and South Africa using the DNeasy blood and tissue kit (QIAgen) according to the manufacturer's protocol and was quantified using a Qubit fluorometer (Life Technologies, Invitrogen).

The pools of genomic DNA were whole genome amplified (WGA) using the REPLI-g midi kit (QIAgen) according to the manufacturer's protocol. Each pool of WGA DNA was subjected to whole genome sequencing on a Roche 454 Genome Sequencer FLX. The raw reads of the WGA DNA sequence were screened directly for microsatellite repeats using MSATCOMMANDER v0.8.2
[39]. Primers flanking the microsatellite repeats were designed using the "Design Primers" option. The sequences of the designed primers were aligned to test for possible identical PCR primer annealing sites.

Initially, a total of 20 primer pairs flanking dinucleotide repeats were selected for validation. These primers were used to amplify 12 individual midge samples (consisting of three individuals from each country) from Kenya, Balearic Islands, Madagascar and South Africa. Samples of $C$. bolitinos midges were also tested for cross-species amplification by these markers. The primers that amplified $100 \%$ of the subpopulation were tagged at the $5^{\prime}$ end with one of the fluorescent dyes FAM, HEX or NED (Table 2). Loci with sufficiently different size ranges were labeled with same dye while those with similar size ranges were labeled with a different dye allowing co-loading of the samples.

\section{Microsatellite analysis}

A total of 143 individuals (Table 1) were genotyped at 12 microsatellite DNA loci (Table 2). Each $25 \mu \mathrm{l}$ PCR reaction included $1.0 \mu \mathrm{l}$ template DNA $(20 \mathrm{ng}), 0.2 \mu \mathrm{mol}$ (each) forward and reverse fluorescent labelled primer (Applied Biosystems, USA), $18 \mu \mathrm{l}$ Platinum PCR supermix high fidelity (Life Technologies) and $2.75 \mu \mathrm{l}$ deionized water (Life Technologies). The amplification was carried out under the following conditions: initial denaturation of $94{ }^{\circ} \mathrm{C}$ for $3 \mathrm{~min}$, then 14 cycles of $94{ }^{\circ} \mathrm{C}$ for $30 \mathrm{~s}, 59^{\circ} \mathrm{C}$ for $30 \mathrm{~s}$ with a gradient decrease of $1{ }^{\circ} \mathrm{C} /$ cycle, $72{ }^{\circ} \mathrm{C}$ for $30 \mathrm{~s}$ followed by 30 cycles of $94{ }^{\circ} \mathrm{C}$ for $30 \mathrm{~s}, 46{ }^{\circ} \mathrm{C}$ for $30 \mathrm{~s}, 72{ }^{\circ} \mathrm{C}$ for $30 \mathrm{~s}$ and a final elongation step of $72{ }^{\circ} \mathrm{C}$ for $7 \mathrm{~min}$. Amplified PCR products were fragment-sized by an external contractor (Macrogen, Geumchun-gu, Seoul). The fragment lengths were analysed and corrected manually using Peak Scanner v2.0 (Applied Biosystems). A fraction (5\%) of the original

Table 2 Culicoides imicola microsatellite primer sequences developed and assessed in this study

\begin{tabular}{|c|c|c|c|c|c|c|}
\hline Locus name & Left primer & Right primer & $\mathrm{NA}$ & Size range & Motif type & Probe DB \\
\hline F1L88 & GTCGGTTGGTGTGTGTCATC & ACGACGACATTATTGACAGCAG & 16 & $180-286$ & $(G T) \wedge 10$ & Pr032368558 \\
\hline F2629 & ACTCTCAAGGTTTCCGCTG & GACGGCAAACAAAACATGCC & 20 & $130-242$ & $(G T) \wedge 9$ & Pr032368559 \\
\hline F2KK2 & ACGTGGTACTCAAAGGCAG & CCATGTGATACAGCTTGCGG & 21 & $166-228$ & $(G T) \wedge 9$ & Pr032368560 \\
\hline F3JMT & CCGATAGTTGTTGTCGTTCATTC & GTATGAGACTCGGTITGCAC & 10 & $212-274$ & $(\mathrm{GT}) \wedge 8$ & Pr032368561 \\
\hline F7ENT & CTGCCTITCCACCTCCAC & ATGCCAGAGTGAAAGCGAC & 12 & $94-198$ & $(A C) \wedge 9$ & Pr032368562 \\
\hline F9RDN ${ }^{\mathrm{b}}$ & AACAAAACACAGCCGCGAG & ATCAGCCAGTCCGCATAAG & 16 & $134-246$ & $(A C) \wedge 9$ & Pr032368563 \\
\hline FHNDU & ACGGGTCCGTGTATTTGTG & GACGAGATACGGGCGAGAG & 14 & $172-198$ & $(A C) \wedge 8$ & Pr032368564 \\
\hline $\mathrm{FIGOO}{ }^{\mathrm{a}}$ & CAGCAATAAATTGTGTGTCATAACC & GCTTCTCACTCTCCAAACATCTG & 15 & $184-226$ & $(G T) \wedge 8$ & Pr032368565 \\
\hline FJEAX & TCACGCCTGAACATGGGAG & AACAACAACAGAGGCAGGC & 11 & $185-210$ & $(G T) \wedge 8$ & Pr032368566 \\
\hline FRB3B & TCCAGCCATCGTCTTTCAG & GGGTGTGTGTAAACTCTATTGTAGC & 15 & $198-234$ & $(A G) \wedge 8$ & Pr032368567 \\
\hline FYCEH & CGCCACGCCATTTATCGTC & ACTGACAGCTTCCTCTCGC & 26 & $108-248$ & $(\mathrm{AC}) \wedge 12$ & Pr032368568 \\
\hline $\mathrm{G} 1 \mathrm{OH} 4$ & TCTCCCAGAAGCGTITGC & GTCGTCGTTCTGCCTTGC & 11 & $98-268$ & $(A C) \wedge 8$ & Pr032368569 \\
\hline
\end{tabular}

a discarded as it was in linkage disequilibrium with loci FHNDU $(P<0.05)$. ${ }^{b}$ excluded from downstream analysis because of too much missing data 
samples was re-run as a validation of initial allelic scores.

\section{Data analysis}

Genepop [40] was used to test for linkage disequilibrium between each pair of loci and across regions (Fischer's method) and to estimate allelic diversity and the coefficient of inbreeding $\left(\mathrm{F}_{\mathrm{IS}}\right)$ at individual loci within populations. Microchecker [41] was used to check for putative null alleles, large allele dropout or stutter peaks.

Departure from the Hardy-Weinberg equilibrium for each locus within each population and a global test across all loci were carried out using Arlequin v3.1 [37]. The observed numbers of heterozygotes and homozygotes at loci in each population were tested against the expected numbers using a chi-square test.

Multilocus genetic distance [42] and fixation index $\left(F_{I S}\right)[37,43]$ estimates were calculated between population pairs using Genepop and Arlequin [37, 40] in order to describe the genetic structure of the populations from the microsatellite data. Permutation tests (100 replications) were used to determine the significance of the population structure estimates.

A model-based clustering method [44] was used to infer population structure probabilistically and assign individuals to populations using the microsatellite data, as implemented in the Bayesian program STRUCTURE v2.3.4 [44]. A total of 22 independent runs and a K value range from 1-10 of the total data sets were carried out. A burn-in period of 100,000, Markov chain Monte Carlo (MCMC) repeats of 100,000, ancestry model of admixture and LOCPRIOR model that used sampling location as prior information were applied to assist clustering. Because replicating STRUCTURE runs creates stochastic effects, resulting in different outcomes, simplifying the assessment of replicate data by calculating medians is important. CLUMPAK [45] was used to collate all the data into a matrix (the Q matrix) of individual membership co-efficient and population ancestry components. CLUMPAK utilizes the LargeKGreedy algorithm of CLUMMP. A total of 2000 repeats were used in this study. STRUCTURE HARVESTER v0.6.94 [46] was used to infer the most likely number of genetic clusters (K) present using both the Evanno and Delta K methods.

The IBD program [47] was used to test for correlation between the pairwise genetic distance $\left(\mathrm{F}_{\mathrm{ST}}\right)$ and the geographic distance matrix with a Mantel test. The statistical significance of this correlation was determined using reduced major axis (RMA) regression, a method specifically formulated to handle errors in the $\mathrm{x}$ and $\mathrm{y}$ variables to reduce bias in estimates of slopes. Error estimates were calculated using three methods: standard linear regression approximations, jackknifing over cases and bootstrapping over cases. Genetic distance was once more regressed against geographic distance omitting the Balearic Islands population that served as an outgroup.

\section{Results \\ Cytochrome oxidase I (COI) gene analysis}

A total of $27 m t$ DNA COI haplotypes were identified in the 94 sequences from both $C$. imicola and $C$. bolitinos $(\mathrm{Hd}=$ 0.8490) (Table 3). Neutrality tests yielded negative values $\mathrm{Fu}$ and Li's F statistic $=-2.18511$ and Tajima's $\mathrm{D}=-1.52771$ but were statistically insignificant $(\mathrm{P}>0.05)$. South Africa, Balearic Islands and Kenya had statistically significant $(P<$ $0.05)$ negative FS value while Mauritius and Kenya had statistically significant $(\mathrm{P}<0.05)$ negative Tajima's $\mathrm{D}$ value (Table 4). The Bayesian skyline plot suggested population growth (Fig. 2).

The haplotype network showed a complex and moderately diversified topology. The network consisted of one main star-like arrangement with satellites and a more complex adjacent network (Fig. 3). The main core group consisted of the East African and southwestern Indian Ocean Islands populations associated with eastern Mediterranean $C$. imicola haplotypes (Greece and Israel). Except for a single haplotype directly linked to the main star-like haplotype, the South Africa population consisted mainly of private haplotypes differing by a few mutations and is organised in an adjacent network. At the intermediate position, the eastern Mediterranean population (Balearic Islands) possessed private haplotypes and so did the C. bolitinos population from Madagascar that served as an out-group (Table 3).

\section{Isolation of microsatellite repeats}

A total of 1450 putative microsatellite repeats were isolated from 367210 reads sequenced. Of these putative microsatellites, 1189 were dinucleotide, 181 were trinucleotide and 80 were tetranucleotide repeats. A total of 465 primers were designed on the flanking regions of the microsatellite repeats. Of these, 249 were found to be similar to each other or blasted to an existing organism in the database and so were considered to be products of contamination. The remaining 216 unique primer pairs were subsequently blasted against the sequenced raw reads. Of these, 169 primer pairs matched a single read (Additional file 1) and 34 primer pairs matched either more than one read or more than one site on a single read. After reverse-complementing the right primer, the primer pairs that were found to match more than one read were aligned to the matching reads. Upon checking the primer point of annealing on individual reads, it was evident that primers matching more than one read were either not properly positioned on the microsatellite repeat flanking regions or matched 
Table 3 A summary of mtDNA COI study collection sites and haplotype distribution

\begin{tabular}{|c|c|c|c|c|c|c|c|c|c|c|c|c|c|c|c|c|c|c|c|c|c|c|c|c|c|c|c|c|}
\hline \multirow[t]{2}{*}{ Region } & \multicolumn{18}{|c|}{ Haplotype } & \multirow[b]{2}{*}{$\mathrm{H} 19$} & \multirow[b]{2}{*}{$\mathrm{H} 2 \mathrm{O}$} & \multirow[b]{2}{*}{$\mathrm{H} 21$} & \multirow[b]{2}{*}{$\mathrm{H} 22$} & \multirow[b]{2}{*}{$\mathrm{H} 23$} & \multirow[b]{2}{*}{$\mathrm{H} 24$} & \multirow[b]{2}{*}{$\mathrm{H} 25$} & \multirow[b]{2}{*}{$\mathrm{H} 26$} & \multirow[b]{2}{*}{$\mathrm{H} 27$} & \multirow[b]{2}{*}{ Totals } \\
\hline & $\mathrm{H} 1$ & $\mathrm{H} 2$ & $\mathrm{H} 3$ & $\mathrm{H} 4$ & $\mathrm{H} 5$ & $\mathrm{H} 6$ & $\mathrm{H} 7$ & $\mathrm{H} 8$ & $\mathrm{H} 9$ & $\mathrm{H} 10$ & $\mathrm{H} 11$ & $\mathrm{H} 12$ & $\mathrm{H} 13$ & $\mathrm{H} 14$ & $\mathrm{H} 15$ & $\mathrm{H} 16$ & $\mathrm{H} 17$ & $\mathrm{H} 18$ & & & & & & & & & & \\
\hline South Africa & 1 & & & & & & & & & & & & & & & & 3 & 1 & 3 & 1 & 1 & 1 & 1 & 1 & & & & 13 \\
\hline Madagascar & & & 10 & 4 & & 1 & & & & & & & & & & & & & & & & & & & & & & 15 \\
\hline Kenya & & & 12 & 2 & 2 & 1 & & & 1 & 2 & 1 & 1 & & & 1 & & & & & & & & & & & & & 23 \\
\hline Israel & & & & & 5 & & & & & & & & & & & & & & & & & & & & 1 & & & 6 \\
\hline Balearic Islands & & & & & & & 13 & 1 & & & & & & & & & & & & & & & & & & & & 14 \\
\hline Greece & & & & & & & & & & & & & & & & & & & & & & & & & & 2 & 3 & 5 \\
\hline Mauritius & & 1 & 11 & & & & & & & & & & & & & 1 & & & & & & & & & & & & 13 \\
\hline C. bolitinos & & & & & & & & & & & & & 1 & 4 & & & & & & & & & & & & & & 5 \\
\hline Total & 1 & 1 & 33 & 6 & 7 & 2 & 13 & 1 & 1 & 2 & 1 & 1 & 1 & 4 & 1 & 1 & 3 & 1 & 3 & 1 & 1 & 1 & 1 & 1 & 1 & 2 & 3 & 94 \\
\hline
\end{tabular}


Table 4 A table of estimates of Tajima's D neutrality test of COI haplotypes C. bolitinos and C. imicola

\begin{tabular}{|c|c|c|c|c|c|c|c|c|c|}
\hline & South Africa & Mauritius & Madagascar & Balearic Islands & Kenya & Israel & Greece & Mean & S.D \\
\hline Sample size & 13 & 13 & 17 & 14 & 21 & 6 & 5 & 11.75 & 5.9 \\
\hline S & 10 & 3 & 3 & 1 & 8 & 2 & 3 & 8.6 & 12.7 \\
\hline$\pi$ & 2.5 & 0.5 & 0.72 & 0.14 & 1.2 & 0.7 & 1.8 & 2.9 & 5.2 \\
\hline Tajima's D & -0.91 & -1.7 & -0.53 & -1.2 & -1.7 & -1.13 & 1.57 & -0.78 & 1.11 \\
\hline P(Tajima's D) & 0.19 & 0.02 & 0.32 & 0.16 & 0.02 & 0.14 & 0.97 & 0.26 & 0.33 \\
\hline FS & -4.3 & -0.69 & -0.92 & -0.59 & -4.06 & 0.95 & 2.43 & -1.03 & 2.45 \\
\hline$P(F S)$ & 0 & 0.08 & 0.15 & 0.02 & 0 & 0.61 & 0.85 & 0.24 & 0. \\
\hline
\end{tabular}

Bold indicate the significant values

sequences outside of the repeat regions. These primer pairs were excluded from the study.

\section{Intra- and inter-population diversity, Hardy-Weinberg equilibrium and linkage disequilibrium}

Substantial variation was observed among the 12 microsatellite loci used to genotype the individual $C$. imicola midges (Table 2 and Additional file 2). Exact tests for linkage disequilibrium showed a significant association between the loci FIGOO and FHNDU. The locus FIGOO was discarded, as it did not result in further linkage disequilibrium. Locus F9RDN was also discarded because it resulted in high null amplification (19\%). A total of 187 alleles were scored ranging from 11-26 alleles/locus (Table 2). Initial tests conducted for each locus in all populations indicated statistical significance of departure from Hardy-Weinberg equilibrium $(\mathrm{P}<0.05)$ in $71 \%$ of the instances. The expected genetic diversity $\left(\mathrm{H}_{\mathrm{e}}\right)$ varied from 0.2 to 0.94 while the observed heterozygosity $\left(\mathrm{H}_{\mathrm{o}}\right)$ ranged from 0.125 to 1.0. Putative null alleles were identified at some loci in some populations using Microchecker. The null alleles were not locus-specific (Additional file 2 ). To check for congruence in the results, a total of 77 DNA samples that were initially identified either as homozygotes at one or more of the 12 loci or had failed to amplify were re-amplified using a touchdown PCR program. Two samples (3\%) failed to successfully re-amplify, ten samples (13\%) initially scored as homozygous were scored as heterozygous, six samples (8\%) initially scored as heterozygotes were scored as homozygotes while 17 samples (22\%) scored as null were successfully re-amplified and 42 samples (56 \%) were un-altered. A third run was carried out to

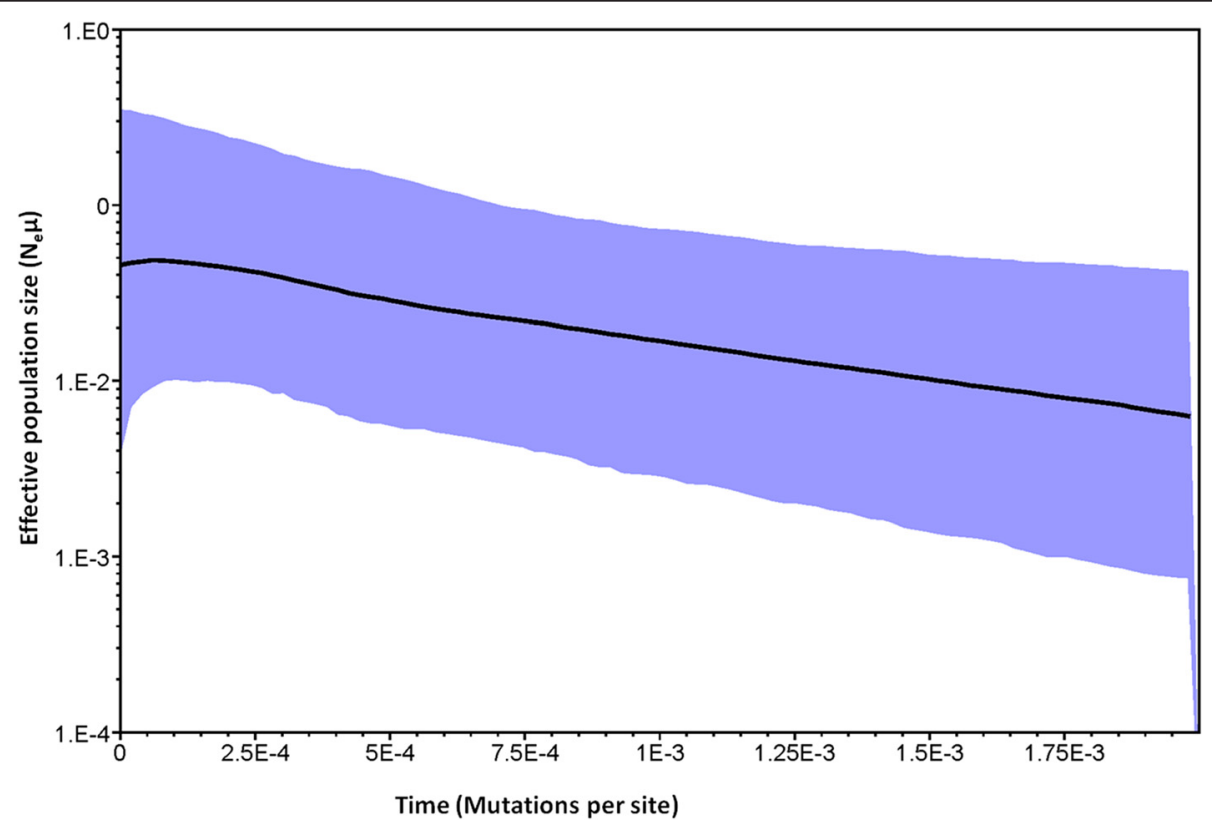

Fig. 2 Bayesian skyline plot based on partial sequences of the mitochondrial region. $X$ axis represents time measured in mutation units per

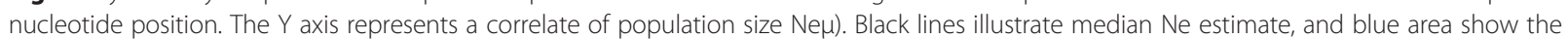
$95 \%$ confidence interval 


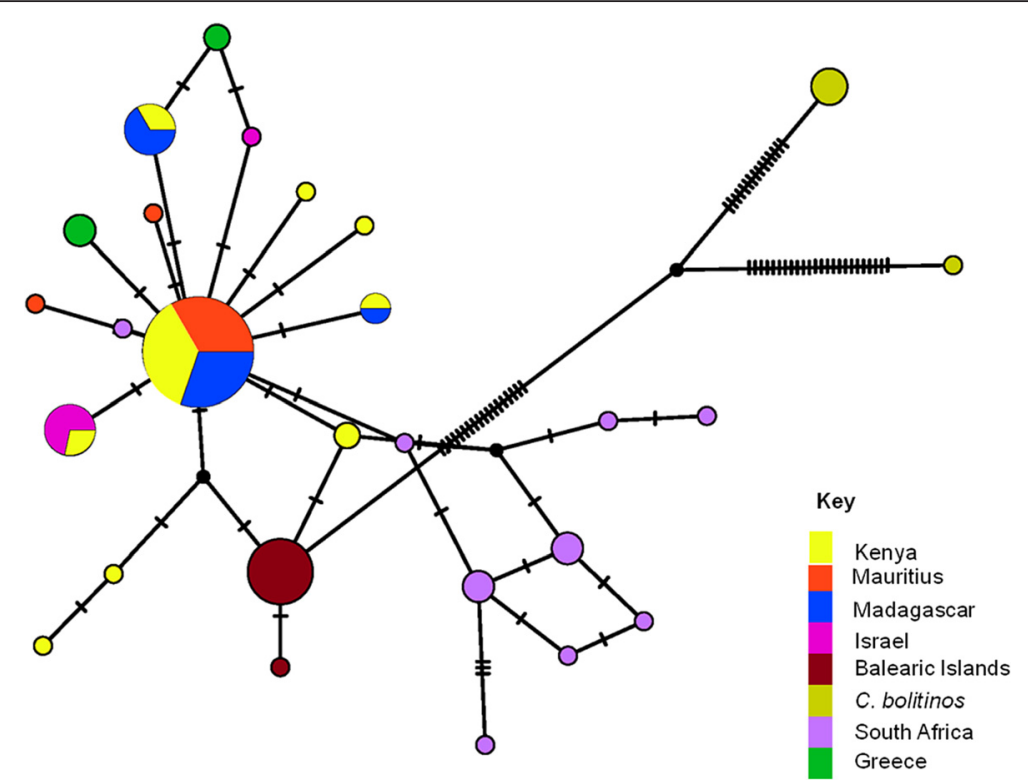

Fig. 3 Haplotype networks of C. imicola COI sequences from the Mediterranean, Africa and C. bolitinos from Madagascar. Each circle represents a sequence; the size of the circle is proportional to number of individuals in possession of the particular haplotype sequence. The connections are mutational steps between individuals

amplify all the individuals that failed at the two previous attempts.

Population differentiation and isolation by distance (IBD) Statistically significant genetic differentiation $(P<0.05)$ was demonstrated between the Balearic Islands population and all the other populations [Balearic Islands vs. Madagascar $\left(\mathrm{F}_{\mathrm{ST}}=0.08\right)$, Balearic Islands vs. Mauritius $\left(\mathrm{F}_{\mathrm{ST}}=0.09\right)$, Balearic Islands vs. South Africa $\left(\mathrm{F}_{\mathrm{ST}}=0.14\right)$, Balearic Islands vs. Kenya $\left.\left(\mathrm{F}_{\mathrm{ST}}=0.08\right)\right]$. The rest of the African populations seemed to have no genetic differentiation except between the Kenyan population and South African $\left(\mathrm{F}_{\mathrm{ST}}=0.07\right)$ and South Africa and Madagascar populations $\left(\mathrm{F}_{\mathrm{ST}}=0.06\right)$ in the tests employed (Table 5). $\mathrm{F}_{\mathrm{ST}}$ estimates varied from 0.02 to 0.14 . In spite of being geographically closer (approximately $2040 \mathrm{~km}$ ) the $\mathrm{F}_{\mathrm{ST}}$ value of the South Africa and Madagascar populations was higher $\left(\mathrm{F}_{\mathrm{ST}}=0.06\right)$ than the $\mathrm{F}_{\mathrm{ST}}$ value between the South Africa and Mauritius populations $\left(\mathrm{F}_{\mathrm{ST}}=0.02\right)$ (approximately $3090 \mathrm{~km}$ ) (Table 5). The results of the Mantel test for correlation between genetic distance and geographic distance matrix supported a significant positive correlation $\left(r^{2}=0.607\right.$, Mantel probability $\left.p=0.0079\right)$ (Fig. 4). The null hypothesis of no correlation between geographical and genetic distance was therefore rejected. When the correlation test was re-run after omitting the Balearic Islands population, a non-significant positive correlation did not support IBD effect.

\section{Bayesian analysis of population differentiation}

Evanno and Delta methods identified the most probable clustering values of $\mathrm{K}=3$ (Fig. 5). The coloured columns in the matrix show the inferred ancestry membership proportional probabilities of each individual. The posterior probabilities suggested that C. bolitinos individuals were not admixed. As a whole, C. imicola populations demonstrated admixture. However, the Balearic Islands

Table 5 A matrix of pairwise estimates of genetic distance $\left(F_{S T}\right)$ (below diagonal) and geographic distances (Km) (above diagonal) of microsatellite DNA of C. imicola populations from Balearic Islands and Africa

\begin{tabular}{|c|c|c|c|c|c|}
\hline & Kenya & Balearic Islands & Madagascar & Mauritius & South Africa \\
\hline Kenya & & 5970 & 2550 & 3290 & 3010 \\
\hline Balearic Islands & $0.08(0.00+-0.00)$ & & 8490 & 9230 & 8030 \\
\hline Madagascar & $0.03(0.00+-0.00)$ & $0.08(0.00+-0.00)$ & & 1120 & 2040 \\
\hline Mauritius & $0.03(0.00+-0.00)$ & $0.09(0.00+-0.00)$ & $0.02(0.00+-0.00)$ & & 3090 \\
\hline South Africa & $0.07(0.00+-0.00)$ & $0.14(0.00+-0.00)$ & $0.06(0.00+-0.00)$ & $0.02(0.00+-0.00)$ & \\
\hline
\end{tabular}

Bold values are statistically significant $(p<0.05)$ 


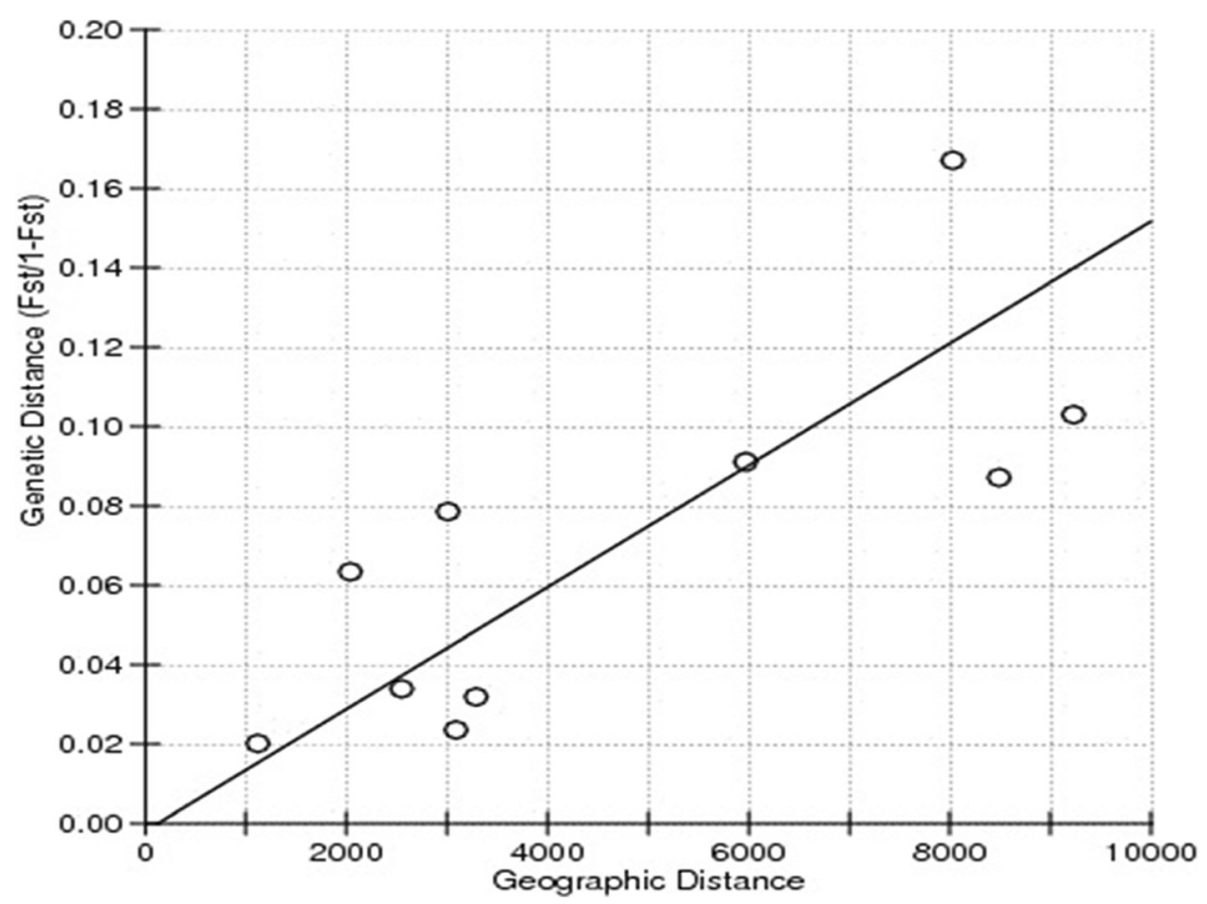

Fig. 4 Mantel test for correlation between the pairwise genetic distance and the geographic distance matrix. Regression analysis of pairwise genetic distance $\left(F_{S T} / 1-F_{S T}\right)$ regressed on pairwise geographic distance $(\mathrm{Km})$ between collection sites revealed a significant positive correlation $\left(r^{2}=0.607\right.$, mantel probability $=0.0079(P<0.05)$

and C. bolitinos population showed a very distinct pattern.

\section{Discussion}

Long distance wind dispersal of Culicoides has been incriminated for the introduction of novel bluetongue virus serotypes and genotypes to new areas [22-24]. Because of their small size, Culicoides can be passively dispersed over long distance by prevailing winds [21]. The microsatellite results of this study revealed gene flow patterns between Kenya and south-west Indian Ocean Islands (Madagascar and Mauritius) $\left(\mathrm{F}_{\mathrm{ST}}=0.03\right)$ (Table 5) which could be due to passive wind-blown Culicoides by the south-west monsoon winds travelling northwards from the South-west Indian Ocean Island to the Kenyan Coast from April/May to October [48] while the northeast monsoon winds blowing south from the Kenyan coast from December to mid-March could blow the midges to the Islands. Despite a shorter distance between Madagascar and South Africa, the populations show a lower degree of gene flow probably due to the orientation of monsoon winds flow being away from South Africa [48]. However, the Mauritius and South Africa C. imicola populations seemed genetically similar $\left(\mathrm{F}_{\mathrm{ST}}=0.02\right)$ (Table 5). This could underpin alternative ways of dispersal of the vector. Movement due to human activities, especially international animal trade, cannot be ruled out. At a different scale (continental) and using a different set of microsatellite markers [27], Jacquet et al. [28] found $F_{\mathrm{ST}}$ values similar to our study and highlighted a strong differentiation between and within the Meditteranean and African populations of C. imicola.

The lack of genetic homogeneity between the Kenyan and South African populations of C. imicola as shown by microsatellite results $\left(\mathrm{F}_{\mathrm{ST}}=0.07\right)$ (Table 5 ) and the shape of the haplotype network of COI sequences,

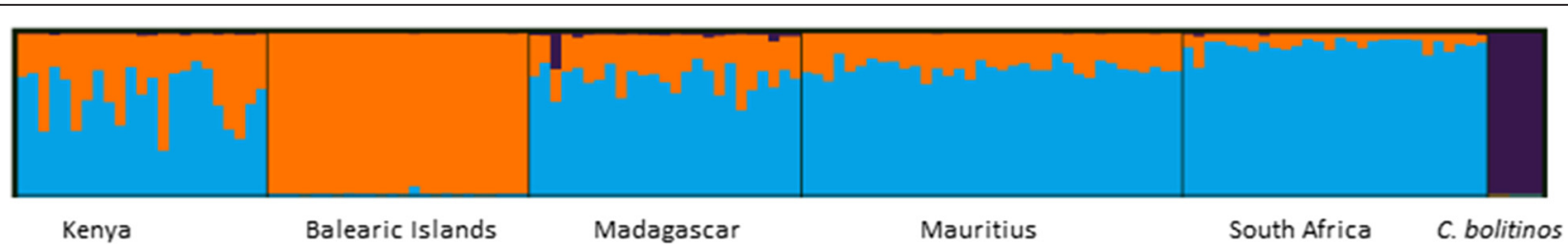

Fig. 5 Plots of cluster assignment of individuals into three founder populations. Each individual is represented by a single vertical line, partitioned into K-colored segments that represent the individual's estimated membership fraction in each of the inferred cluster 
suggest limits to gene flow. Physical and/or anthropogenic barriers could occur. The spatial distribution of C. imicola is highly dependent on soil type and soil moisture for breeding sites, in habitats open to sunlight [5, 49]. A similar pattern was observed for Anopheles gambiae Giles and Anopheles funestus Giles in Africa in which population structures resulting in split between lineages are thought to have arisen due to extreme past droughts in East Africa [50, 51].

A phylogenetic study of C. brevitarsis, another member of the Imicola Complex, in the Australasian region showed no evidence of genetic separation or structure between populations sampled from northern and eastern Australia, approximately $3000 \mathrm{~km}$ apart, suggesting a panmictic population in the continent [30]. The breeding habitat of C. brevitarsis is restricted to fresh dung of wild and domesticated bovids [52]. Its distribution in Australia, within its climatic niche, coincides with the distribution of cattle [53] suggesting that this species of biting midge could not have existed in Australia before the introduction of cattle to the continent in the late 19th Century [54]. Therefore, the genetic connectivity that is evident among the populations of C. brevitarsis within Australia could be an indication of a recent colonization and expansion into this region [30]; this is in contrast to probably longer past history of C. imicola in South Africa and Kenya.

Model-based clustering method used to infer structure in this study identified that three-cluster was most probable. The $\mathrm{K}=3$ model scenario suggests a single homogenous population of the African C. imicola populations sampled and genetically distinct Balearic Islands and C. bolitinos populations.

This study has revealed a significant positive correlation between genetic distance and geographic distance for $C$. imicola, indicative of IBD pattern. Isolation by distance, initially described by Wright [55], describes an accumulation of local genetic differences under geographically restricted dispersal [56]. Thus, neighboring populations exchange more migrants than the distant ones, resulting in a significant decline in gene flow with distance. Previous population genetic studies have reported a fine scale IBD pattern among damselflies brought about by their sedentary nature which leads to restricted movements and localized breeding [57], while Lehmann [50] found that distance contributed minimally to the IBD pattern in the African populations of the malaria vector, Anopheles gambiae. In the present study, the IBD pattern disappears when the geographically outlying population of Balearic Islands is excluded, suggesting that the pattern may be due to vicariance resulting from reduced gene flow between the geographically outlying Balearic Islands population and the southern and eastern African populations of C. imicola that we have sampled [58].
The microsatellite markers isolated in this study were variable. The departure from Hardy-Weinberg equilibrium observed in this study could be as a result of presence of null alleles caused by mutations at locus-specific primer annealing sites, resulting in an excess in homozygosity [59].

The effect of null allele on genetic test of population structure has been shown to result in small upward biases to $\mathrm{F}_{\mathrm{ST}}(0.003-0.004)$ and slight reduction in the power of STRUCTURE to correctly assign individuals to populations (0.2 and $0.1 \%$ units) [60]. With these caveats, we argue that the likely slight upward biases in population genetic structure parameters and specimen cluster assignments using STRUCTURE will not drastically alter the results of our study.

Twelve microsatellite markers isolated in this study from the C. imicola genome were also detected in our few $C$. bolitinos individuals. All the loci were amplified and the alleles were quite varied. This species is more closely related phylogenetically to $C$. brevitarsis and could be a better vector of BTV than C. imicola [61]. The development of genetic markers that are capable of deciphering the genetic structure of this species will be very useful in studying their populations in the African region.

The mitochondrial COI gene haplotype network corroborated to a great extent the microsatellite results. Kenya and south-west Indian Ocean Islands (Mauritius and Madagascar) shared haplotypes. Except for a single haplotype which was directly linked to the main haplotype, South Africa population mainly possessed private haplotypes. This could be indicative of a contemporary only modest matrilineal gene flow between east and south of Africa. The Kenyan and south-west Indian Ocean populations shared haplotypes with the eastern Mediterranean populations of C. imicola (Israel and Greece). The western Mediterranean population (Balearic Islands) had private haplotypes. This could be indicative of different routes of C. imicola dispersal in the Mediterranean region [62] as proposed by Jacquet et al. [28] . However, a more detailed and extensive sampling and multiple loci population genetic study would be required to substantiate this claim.

The Bayesian skyline plot suggested a population growth, compatible with the star-like pattern of the Kenya/south-west Indian Ocean Islands mitochondrial marker haplotype network and the Tajima's D and Fu's F test values for Kenya, South Africa and Mauritius. This could be indicative of a recent increase in favourable conditions that increased suitable habitats but also expansions of its distributions in territories where bovids and equids, domesticated or wild were absent for a long time or changing farming practices cannot be ruled out. However the Bayesian skyline plot ought to be interpreted with caution as Bayesian skyline plot appears to 
slightly overestimate the most recent population [38]. More extensive analytical procedures need to be employed in order to prove this claim.

This study showed a higher frequency of private haplotypes among the South African C. imicola population as well as the highest nucleotide diversity. This may suggest an ancestral history, reinforced by the closely related species described from the region [63-65]

\section{Conclusions}

The findings of this study demonstrate notable risk of movement of Culicoides- borne virus within the East and South regions of Africa, especially between Kenya and neighboring islands (Mauritius, Madagascar), demonstrated by two types of genetic markers and analysis. This risk is probably due to passive wind-borne infected Culicoides, implicating the monsoon winds in the Indian Ocean. Such vector midge movement could impact negatively on local livestock production and equids industry. On the other hand, we found a reduction in Culicoides genetic flow within the continental mainland, between South Africa and Kenya. The microsatellite markers isolated in this study could be applied in genotyping C. bolitinos, another important vector of BTV and AHSV in the region.

\section{Additional files}

\section{Additional file 1: A summary of the $C$. imicola markers designed to the flanking regions of the microsatellite repeats with the type of repeats. The table provides a list of a total of 169 primer pairs predicted to anneal to a unique single pair read. The motif type that the primer represents is also indicated (XLS $41 \mathrm{~kb}$ ) \\ Additional file 2: A table of estimates of genetic diversity of the microsatellite markers per population. The table describes the genetic diversity of the markers. Significant Hardy-Weinberg equilibrium $(P<0.05)$ tests are in BOLD. The expected gene diversity $\left(H_{\mathrm{e}}\right)$ varied from $(0.2-0.94)$ while the observed heterozygosity $\left(H_{0}\right)$ ranged from $(0.125-1.0)$. Putative null alleles were identified at some loci in some populations using Micro- checker. The null alleles were not locus specific. $\mathrm{H}_{\mathrm{o}}$ - Observed hetero- zygosity; $\mathrm{H}_{\mathrm{e}}$ - Expected heterozygosity; $\mathrm{P}_{\text {HwE }}$ - Probability of Hardy- Weinberg equilibrium; $\mathrm{F}_{\mathrm{IS}^{-}}$Inbreeding coefficient; $\mathrm{N}_{\text {allele }}$ - Null allele; $\mathrm{n}$ - number of Samples (XLS $29 \mathrm{~kb}$ )}

\section{Competing interests}

The authors declare that they have no competing interests.

\begin{abstract}
Authors' contribution
MGO: Designed, conducted the experiments, sampled, analysed results and drafted the paper. GNM: Participated in the whole genome sequencing. MO: Participated in microsatellite scoring. GJV: Did the sampling and specimen identification. MM: Did the sampling and specimen identification. NE: Did the sampling and specimen identification. AD: Participated in the study design. SK: Participated in the study design. PJW: Involved in the study design and writing of the manuscript. JBD: Involved in the study design, experimental design and writing of the manuscript. All authors read and approved the final version of the manuscript
\end{abstract}

\section{Acknowledgement}

M.G. Onyango was supported by a scholarship from the Australian Aid Program of the Department of Foreign Affairs and Trade. Our gratitude goes to Johnson Mak (Deakin University and CSIRO) and Nigel Beebe (University of Queensland and (SIRO) for incisive suggestions and discussions. Laboratory works at AAHL have been partly performed thanks to the National Collaborative Research Infrastructure Strategy of Australia. We would also like to extend our gratitude to Doreen Busigye for assistance with the geographical maps and Ricardo Del Rio-Lopez for assistance in the sampling of Balearic specimens. We thank Christophe Rogier, director of the Institut Pasteur of Madagascar, the AnimalRisk OI project, and Vincent Michel Rakotoharinome, Direction des Services Vétérinaires au Ministère de l'Elevage for facilitating the sampling in Madagascar.

\section{Author details}

'CSIRO Health and Biosecurity, Australian Animal Health Laboratory, 5 Portalington Road, Geelong, VIC 3220, Australia. ${ }^{2}$ School of Medicine, Deakin University, 75 Pidgons Road, Waurn Ponds, VIC 3216, Australia. ${ }^{3}$ International Livestock Research Institute, P.O. Box 3070900100 Nairobi, Kenya.

${ }^{4}$ ARC-Onderstepoort Veterinary Institute, Private bag X5, Onderstepoort 0110, South Africa. ${ }^{5}$ Laboratoria de Zoologia, University of the Balearic Islands, Palma de Mallorca CP: 07122, Spain. ${ }^{6}$ Institut Pasteur of Madagascar, B.P. 1274 Ambatofotsikely, 101 Antananarivo, Republic of Madagascar.

${ }^{7}$ Biosciences eastern and central Africa - ILRI Hub (BecA-ILRI Hub), ILRI, PO Box 3070900100 Nairobi, Kenya.

Received: 26 August 2015 Accepted: 19 December 2015

Published online: 24 December 2015

References

1. Nevill H, Venter GJ, Meiswinkel R, Nevill EM. Comparative descriptions of the pupae of five species of the Culicoides imicola complex (Diptera, Ceratopogonidae ) from South Africa. Onderstepoort J Vet Res. 2007;114:97-114.

2. Bellis GA, Dyce AL, Gopurenko D, Yanase T, Garros C, Labuschagne K, et al. Revision of the Culicoides (Avaritia) imicola complex Khamala \& Kettle (Diptera: Ceratopogonidae) from the Australasian region. Zootaxa. 2014;3768:401-27.

3. Meiswinkel R. Adult characters defining and separating the Imicola and Orientalis species complexes of the subgenus Avaritia Fox. Culicoides, Diptera: Ceratopogonidae. Vet Ital. 1955;2004(40):345-51.

4. Meiswinkel R, Gomulski LM, Goffredo M, Gasperi G. The taxonomy of Culicoides vector complexes - unfinished business. Vet Ital. 2004;40:151-9.

5. Conte A, Goffredo M, Ippoliti C, Meiswinkel R. Influence of biotic and abiotic factors on the distribution and abundance of Culicoides imicola and the Obsoletus Complex in Italy. Vet Parasitol. 2007;150:333-44.

6. Dallas JF, Cruickshank RH, Linton YM, Nolan DV, Patakakis M, Braverman Y, et al. Phylogenetic status and matrilineal structure of the biting midge, Culicoides imicola, in Portugal, Rhodes and Israel. Med Vet Entomol. 2003;17:379-87.

7. Venter GJ, Wright IM, Van Der Linde TC, Paweska JT. The oral susceptibility of South African field populations of Culicoides to African horse sickness virus. Med Vet Entomol. 2009;23:367-78.

8. Sellers RF. Bluetongue in Africa, the Mediterranean region and near east-Disease, virus and vectors. Prev Vet Med. 1984:2:371-8.

9. Sperlova A, Zendulkova D. Bluetongue: a review. Vet Med (Praha). 2011;56:430-52.

10. Bhanuprakash V, Indrani B, Hosamani M, Balamurugan V, Singh R. Bluetongue vaccines: the past, present and future. Expert Rev Vaccines. 2009;8:191-204.

11. Gerdes GH. A South African overview of the virus, vectors, surveillance and unique features of bluetongue. Vet Ital. 2004;40:39-42.

12. Davies FG. Bluetongue studies with sentinel cattle in Kenya. J Hyg (Lond). 1978:80:197-204.

13. Andriamandimby Fy S, Viarouge C, Ravalohery J-P, Reynes J-M, Sailleau C, Tantely ML, et al. Detection in and circulation of Bluetongue virus among domestic ruminants in Madagascar. Vet Microbiol. 2015;176:268-73.

14. Bréard E, Sailleau C, Hamblin C, Zientara S. Bluetongue virus in the French Island of Reunion. Vet Microbiol. 2005;106:157-65.

15. Jori F, Roger M, Baldet T, Delécolle J, Sauzier J, Jaumally M, et al. Orbiviruses in Rusa Deer, Mauritius, 2007. Emerg Infect Dis. 2011;17:312-3.

16. Mellor P. The transmission and geographical spread of African horse sickness and bluetongue viruses. Ann Trop Med Parasitol. 1995;89:1-15. 
17. Mellor PS, Hamblin C. African horse sickness. Vet Res. 2004;35:445-66.

18. Sailleau C, Hamblin C, Paweska JT, Zientara S. Identification and differentiation of the nine African horse sickness virus serotypes by RT-PCR amplification of the serotype-specific genome segment 2. J Gen Virol. 2000;81:831-7.

19. Coetzer JA, Guthrie AJ. African horse sickness. In: Infectious diseases of livestock. 2nd ed. Southern Africa, Cape town: Oxford Univ Press; 2004. p. 1231-46.

20. Koekemoer JJO. Serotype-specific detection of African horsesickness virus by real-time PCR and the influence of genetic variations. J Virol Methods. 2008;154:104-10

21. Sellers RF. Weather, host and vector-their interplay in the spread of insect-borne animal virus diseases. J Hyg (Lond). 1980;85:65-102.

22. Ducheyne E, De Deken R, Bécu S, Codina B, Nomikou K. Quantifying the wind dispersal of Culicoides species in Greece and Bulgaria. Geospat Health. 2007;2:177-89.

23. Eagles D, Deveson T, Walker PJ, Zalucki MP, Durr P. Evaluation of longdistance dispersal of Culicoides midges into northern Australia using a migration model. Med Vet Entomol. 2012;26:334-40.

24. Hendrickx G, Gilbert M, Staubach C, Elbers A, Mintiens K, Gerbier G, et al. A wind density model to quantify the airborne spread of Culicoides species during north-western Europe bluetongue epidemic, 2006. Prev Vet Med. 2008;87:162-81.

25. Toye PG, Batten CA, Kiara H, Henstock MR, Edwards L, Thumbi S, et al. Bluetongue and Epizootic Haemorrhagic Disease virus in local breeds of cattle in Kenya. Res Vet Sci. 2013;94:769-73.

26. Sebastiani F, Meiswinkel R, Gomulski LM, Guglielmino CR, Mellor PS, Malacrida AR, et al. Molecular differentiation of the Old World Culicoides imicola species complex (Diptera, Ceratopogonidae), inferred using random amplified polymorphic DNA markers. Mol Ecol. 2001;10:1773-86.

27. Mardulyn P, Goffredo M, Conte A, Hendrickx G, Meiswinkel R, Balenghien $T$, et al. Climate change and the spread of vector-borne diseases: using approximate Bayesian computation to compare invasion scenarios for the bluetongue virus vector Culicoides imicola in Italy. Mol Ecol. 2013;22:2456-66.

28. Jacquet S, Garros C, Lombaert E, Walton C, Restrepo J, Allene X, et al. Colonization of the Mediterranean Basin by the vector biting midge species Culicoides imicola : an old story. Mol Ecol. 2015;24:5707-25.

29. Desvars A, Grimaud Y, Guis H, Esnault O, Allène $X$, Gardès L, et al. First overview of the Culicoides Latreille (Diptera: Ceratopogonidae) livestock associated species of Reunion Island, Indian Ocean. Acta Trop. 2015;142:5-19.

30. Onyango M, Beebe NW, Gopurenko D, Bellis GA, Nicholas A, Ogugo M, et al. Assessment of population genetic structure in the arbovirus vector midge, Culicoides brevitarsis (Diptera: Ceratopogonidae), using multi-locus DNA microsatellites. Vet Res. 2015:46:108.

31. Glick Jl. Culicoides biting midges (Diptera: Ceratopogonidae ) of Kenya. J Med Entomol. 1990;27.

32. Bellis GA, Dyce AL, Gopurenko D, Mitchell A. Revision of the Immaculatus Group of Culicoides Latreille (Diptera: Ceratopogonidae) from the Australasian Region with description of two new species. Zootaxa. 2013:3680:15-37.

33. Edgar RC. MUSCLE: multiple sequence alignment with high accuracy and high throughput. Nucleic Acids Res. 2004;32:1792-7.

34. Nolan DV, Dallas JF, Piertney SB, Mordue AJ. Incursion and range expansion in the bluetongue vector Culicoides imicola in the Mediterranean basin: A phylogeographic analysis. Med Vet Entomol. 2008:22:340-51.

35. Leigh J, Bryant D. POPART: full-feature software for haplotype network construction. Methods Ecol Evol. 2015;6:1110-6.

36. Librado P, Rozas J. DnaSP v5: A software for comprehensive analysis of DNA polymorphism data. Bioinformatics. 2009;25:1451-2.

37. Excoffier L, Laval G, Schneider S. Arlequin ( version 3.0 ): An integrated software package for population genetics data analysis. Evol bionformatics. 2007;1:47-50.

38. Drummond AJ. Bayesian Coalescent Inference of Past Population Dynamics from Molecular Sequences. Mol Biol Evol. 2005;22:1185-92.

39. Faircloth BC. Msatcommander: Detection of Microsatellite Repeat Arrays and Automated, Locus-Specific Primer Design. Mol Ecol Resour. 2008;8:92-4.
40. Rousset F. genepop'007: a complete re-implementation of the genepop software for Windows and Linux. Mol Ecol Resour. 2008;8:103-6.

41. Van Oosterhout C, Hutchinson WF, Wills DPM, Shipley P. Micro-Checker: Software for Identifying and Correcting Genotyping Errors in Microsatellite Data. Mol Ecol Notes. 2004;4:535-8.

42. Nei M. Estimation of Average Heterozygosity and genetic distance from a small number of individuals. Genetics. 1978:89:583-90.

43. Weir BS, Cockerham CC. Estimating F-Statistics for the Analysis of Population Structure. Evolution (N Y). 1984;38:1358-70.

44. Pritchard JK, Stephens M, Donnelly P. Inference of Population Structure Using Multilocus Genotype Data. Genetics. 2000;155:945-59.

45. Kopelman NM, Mayzel J, Jakobsson M, Rosenberg NA, Mayrose I. Clumpak: a program for identifying clustering modes and packaging population structure inferences across K. Mol Ecol Resour. 2015;15:1179-91.

46. Evanno G, Regnaut S, Goudet J. Detecting the number of clusters of individuals using the software STRUCTURE: a simulation study. Mol Ecol. 2005;14:2611-20.

47. Bohonak AJ. IBD (Isolation by Distance): a program for analyses of isolation by distance. J Hered. 2002;93:153-4.

48. Hastenrath $S$, Greischar $L$. The monsoonal current regimes of the tropical Indian Ocean: Observed surface flow fields and their geostrophic and wind-driven components. J Geophys Res. 1991;96:12619-33.

49. Acevedo P, Ruiz-Fons F, Estrada R, Márquez AL, Miranda MA, Gortázar C, et al. A broad assessment of factors determining Culicoides imicola abundance: modelling the present and forecasting its future in climate change scenarios. PLOS ONE. 2010;5:e14236.

50. Lehmann T, Licht M, Elissa N, Maega BTA, Chimumbwa JM, Watsenga FT, et al. Population structure of Anopheles gambiae in Africa. J Hered. 2003;94:133-47.

51. Michel AP, Ingrasci MJ, Schemerhorn BJ, Kern M, Le Goff G, Coetzee M, et al. Rangewide population genetic structure of the African malaria vector Anopheles funestus. Mol Ecol. 2005;14:4235-48.

52. Verhoef FA, Venter GJ, Weldon CW. Thermal limits of two biting midges, Culicoides imicola Kieffer and C. bolitinos Meiswinkel (Diptera: Ceratopogonidae). Parasit Vectors. 2014;7:384.

53. St George TD, Baldock C, Bellis G, Bishop A, Cameron A, Doherty B, et al. The History of Bluetongue, Akabane and Ephemeral Fever Viruses and Their Vectors in Australia, National Arbovirus Monitoring (NAMP) Report. 1999. p. 101.

54. Dyce AL. Distribution of Culicoides (Avaritia) species (Diptera: Ceratopogonidae) west of the Pacific ocean. In: Proceedings of the third symposium. CSIRO and QIMR, Brisbane. 1982. p. 35-43.

55. Wright S. Isolation by distance. Genetics. 1943;28:114-38.

56. Slatkin M. Isolation by Distance in Equilibrium and Non-Equilibrium Populations. Evolution (NY). 1993:47:264-79.

57. Watts PC, Rouquette JR, Saccheri IJ, Kemp SJ, Thompson DJ. Molecular and ecological evidence for small-scale isolation by distance in an endangered damselfly, Coenagrion mercuriale. Mol Ecol. 2004;13:2931-45.

58. Peterson MA, Denno RF. The influence of dispersal and diet breadth on patterns of genetic isolation by distance in phytophagous insects. Am Nat. 1998;152:428-46.

59. Kelly AC, Mateus-Pinilla NE, Douglas M, Douglas M, Shelton P, Novakofski J. Microsatellites behaving badly: empirical evaluation of genotyping errors and subsequent impacts on population studies. Genet Mol Res. 2011:10:2534-53.

60. Carlsson J. Effects of microsatellite null alleles on assignment testing. Hered. 2008;99:616-23.

61. Paweska JT, Venter GJ, Mellor PS. Vector competence of South African Culicoides species for bluetongue virus serotype 1 (BTV-1) with special reference to the effect of temperature on the rate of virus replication in $C$ imicola and C. bolitinos. Med Vet Entomol. 2002;1:10-21.

62. Calvo JH, Calvete C, Martinez-Royo A, Estrada R, Miranda MA, Borras D, et al. Variations in the mitochondrial cytochrome c oxidase subunit I gene indicate northward expanding populations of Culicoides imicola in Spain. Bull Entomol Res. 2009;99:583-91.

63. Meiswinkel R. Afrotropical Culicoides: C (Avatitia) loxodontis sp. nov., a new member of the Imicola group (Diptera: Ceratopogonidae) associated with the african elephant in the Kruger National Park, South Africa. Onderstepoort J Vet. 1992;160:145-60. 
64. Meiswinkel R. Afrotropical Culicoides: A redescription of C. (Avaritia) kanagai Khamala \& Kettle, 1971, reared from elephant dung in the Kruger National Park, South Africa. Onderstepoort J Vet. 1987:54:585-90.

65. Meiswinkel R. Afrotropical Culicoides: A redescription of C. (Avaritia) imicola Kieffer, 1913 (Diptera: Ceratopogonidae) with description of the closely allied C. (A.) bolitinos sp. nov. reared from the dung of the African buffalo, blue wildebeest and cattle in South Africa. Onderstepoort J vet. 1989;56:23-39.

Submit your next manuscript to BioMed Central and we will help you at every step:

- We accept pre-submission inquiries

- Our selector tool helps you to find the most relevant journal

- We provide round the clock customer support

- Convenient online submission

- Thorough peer review

- Inclusion in PubMed and all major indexing services

- Maximum visibility for your research

Submit your manuscript at www.biomedcentral.com/submit 